\title{
Comparative Evaluation of Flexural Strength of Two Newer Composite Resin Materials: An in Vitro Study
}

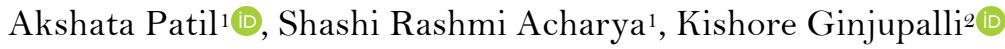

\begin{abstract}
'Department of Conservative Dentistry \& Endodontics, Manipal College of Dental Sciences, Manipal, Manipal Academy of Higher Education, Manipal, Karnataka, India.

${ }^{2}$ Department of Dental materials, Manipal College of Dental Sciences, Manipal, Manipal Academy of Higher Education, Manipal, Karnataka, India.
\end{abstract}

Correspondence: Dr. Shashi Rashmi Acharya, Professor, Department of Conservative Dentistry \& Endodontics, Manipal College of Dental Sciences, Manipal, Manipal Academy of Higher Education, Karnataka, India. E-mail: sracharya@manipal.edu

Academic Editor: Catarina Ribeiro Barros de Alencar

Received: 26 July 2020 / Review: 09 October 2020 / Accepted: 28 December 2020

How to cite: Patil A, Acharya SR, Ginjupalli K. Comparative evaluation of flexural strength of two newer composite resin
materials - an in vitro study. Pesqui Bras Odontopediatria Clín Integr. $2021 ; \quad 21: e 0175$.
https://doi.org/10.1590/pboci.202 1.071

\begin{abstract}
Objective: To evaluate in vitro the flexural strength of two newer composite resin materials. Material and Methods: Twenty-four samples were equally divided into two groups: G1 - Brilliant EverGlow and G2: Brilliant NG. The rectangular blocks of $25 \mathrm{~mm}$ in length, $2 \mathrm{~mm}$ in width and thickness were prepared from two composite materials. Blocks were created by applying composites to a customized split mold and formed between two parallel glass plates. Before light-curing, blocks were covered with Mylar strips and rinsed for 10 seconds in water. Subsequently, they were stored in distilled water for 24 hours at $37^{\circ} \mathrm{C}$ and $100 \%$ humidity before testing. Each sample was placed within a suitable framework of aluminum. The length of gap between the support was $21 \mathrm{~mm}$ and the speed of crosshead at $1 \mathrm{~mm} /$ minute. The data were subjected to an independent t-test. The level of significance was set at $p<0.05$. Results: A less flexural strength was observed in G1 (77.43 Mpa) compared to G2 (118.70 Mpa) ( $<<0.001)$. Conclusion: Universal nanohybrid composite resin material was found to have greater flexural strength than universal submicron hybrid composite material.
\end{abstract}

Keywords: Dental Materials; Composite Resins; Flexural Strength. 


\section{Introduction}

Esthetic restorative resins are the most favored materials for restoration because of modifications in their physical, mechanical and optical properties. Various fillers and resin systems have recently been upgraded or applied to restorative materials for better restorations' clinical performance. Previous studies have documented improvements in elastic modulus, flexural strength, compressive strength, diametric tensile strength, stiffness, fracture strength and wear resistance of these newer composite resins [1-3]. In contrast to traditional resins, nanocomposites thus react much better to the functional stresses. Composite resins for stress-bearing surfaces need to be checked since they are still the key concern for the clinical success of composite materials. Nanohybrid composites contain a lower organic matrix percentage and a higher percentage of fillers and exhibit lower polymerization shrinkage than nanofilled composites [4,5]. The structure and viscosity of recent composite materials differ and need to be checked for all the parameters.

Brilliant EverGlow ${ }^{\mathrm{TM}}$ is a universal submicron hybrid composite which, according to the manufacturers, claims outstanding polishability and retention of gloss. The highly esthetic material of universal shades provides smooth consistency, strong wettability, low instrument stickiness, and high abrasion resistance.

Brilliant $\mathrm{NG}^{\mathrm{TM}}$ is a universal nanohybrid composite, which according to the manufactures, simplifies application techniques and produces excellent esthetic performance. In addition to the high nanometric particle content, its pre-polymerized particle filling provides optimum consistency for manipulation and modelling, along with a significant decrease in shrinkage and high gloss surfaces that can be easily achieved. With the Duo Shade system, Brilliant NG is an outstanding alternative that simplifies color selection and great variety for the best esthetic performance.

Material properties are measured under stress by evaluating the physical properties like flexural strength, flexural modulus and fracture strength $[6,7]$. For composite materials, flexural strength is important because composite resins are subject to tension and compression forces, particularly when used to restore cavities under stress $[6,8]$. Thus, this study aimed to evaluate in vitro the flexural strength of two newer composite resin materials.

\section{Material and Methods}

Study Design and Sample

This in-vitro study comprised of 24 samples equally divided into Group 1 - submicron hybrid composite resin material (Brilliant EverGlow - Coltene Whaledent Inc., Cuyahoga Falls, OH, USA) and Group 2 - nanohybrid composite resin material (Brilliant NG - Coltene Whaledent Inc., Cuyahoga Falls, OH, USA). The duration of the study was 30 days.

Sample size was calculated with $80 \%$ power and $5 \%$ alpha to detect a change of 0.8 . Twenty-four rectangular blocks $(\mathrm{n}=12)$ of $25 \mathrm{~mm}$ in length, $2 \mathrm{~mm}$ in width and thickness were prepared from two different composite materials. Blocks were created by applying composites to a customized split mold and formed between two parallel glass plates.

Before light-curing, blocks were covered with mylar strips. Mylar strips were used to achieve a smooth surface. Blocks were then rinsed for 10 seconds in water. Subsequently, blocks were stored in distilled water for 24 hours at $37^{\circ} \mathrm{C}$ and $100 \%$ humidity before testing. Each sample was placed within a suitable framework of aluminum. The length of gap between the support was $21 \mathrm{~mm}$ and the speed of crosshead at 1 $\mathrm{mm} /$ minute $[9,10]$. The compressing loads were applied to the center of specimen using a Universal testing 
machine (Model 3343, Instron Corporation, Canton, MA, USA) [11]. The computer software following specimen failure (Bluehill, Instron Corporation, Canton MA, USA) was used to record values [12].

Statistical Analysis

Results for comparison between groups were subjected to an independent t-test. Using SPSS software, version 20.0 (IBM Corp., Armonk, NY, USA), statistical analysis was performed at significance $\mathrm{p}<0.05$.

\section{Results}

The result shows significantly less flexural strength in Group 1 compared to group 2 (Table 1).

Table 1. Comparison of mean flexural strength in Mpa.

\begin{tabular}{|c|c|c|}
\hline & Brilliant EverGlow & Brilliant NG \\
\hline Mean & 77.43 & 118.70 \\
\hline $\mathrm{SD}$ & 2.651 & 3.901 \\
\hline p-value & & \\
\hline t-value & & \\
\hline Mean Difference & & \\
\hline
\end{tabular}

\section{Discussion}

Nanocomposites consist of submicrometer particles (nanofillers) to further amplify the resins' physical and optical properties. Nanofilled composite's performance and flexural properties are still being explored. Similarly, submicron hybrid composite is a relatively recent product and has not been researched much on its flexural properties. The goal of a new composite resin is to provide enhanced esthetic properties, optical properties, wear resistance, easy handling and decreased polymerization shrinkage [13].

The restorations in the oral environment are subjected to different types of occlusal forces. The flexural strength indicates the material's resistance to fracture when subjected to complex masticatory forces. In the present study, nanohybrid composite showed better flexural strength than submicron hybrid composite. Brilliant NG, a nanohybrid composite, has a filler content of about $80 \%$ by weight and $65 \%$ by volume. Glass fiber particles that improve the material hardness and bending force resistance may be an explanation for fracture resistance [14].

The mean flexural strength (MPa) of nanohybrid composite (Brilliant NG) and submicron hybrid composite (Brilliant Everglow) are presented in Table 1. The null hypothesis was dismissed as there was a substantial difference in flexural strength between the two composites tested when comparing the results obtained. The independent t-test demonstrated a significant difference between the mean flexural strength of nanohybrid composite and submicron hybrid composite $(\mathrm{p}<0.05)$. Flexural strength simulates the use of composites in areas with high stress $[15,16]$. In addition, there is an ISO 4049/2009, with an $80 \mathrm{MPa}$ limit for polymer-based restorative materials, stated by manufacturers to be suitable for occlusal surfaces [17].

Submicron hybrid composite is the material below this ideal value, with a questionable clinical performance in high stress-bearing areas. Also, the present investigation data indicate that composites' filler content does not necessarily impact flexural strength. Samples investigated had almost identical filler content. This would be in accordance with previous studies assessing the functional properties and curing depth of composites $[15,18]$. Because of its low standard deviation, a low variance of coefficient and less complicated 
distribution of cracks than those provided by other test models, such as biaxial flexural test, the flexural strength was performed using a three-point bending test [19,20]. The result of this analysis showed that the nanohybrid composite’s flexural strength was marginally higher.

\section{Conclusion}

Universal nanohybrid composite resin material was found to have greater flexural strength than universal submicron hybrid composite material. Since composite resins have variations in composition and viscosity, further studies need to be conducted for comparative evaluation of other parameters.

\section{Authors' Contributions}

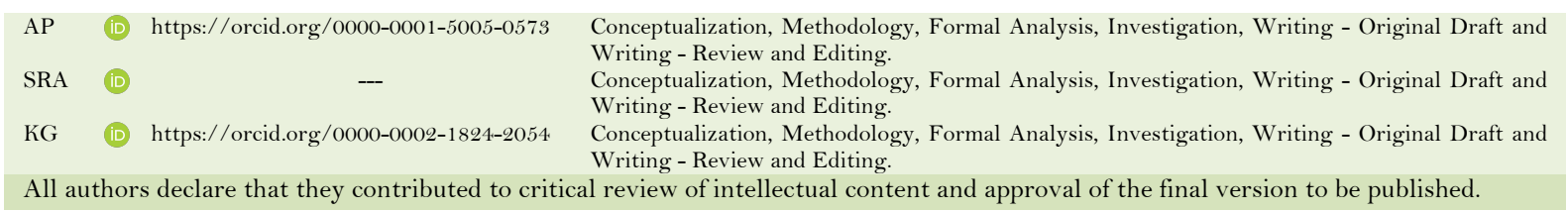

\section{Financial Support}

None.

\section{Conflict of Interest}

The authors declare no conflicts of interest.

\section{Data Availability}

The data used to support the findings of this study can be made available upon request to the corresponding author.

\section{References}

[1] Beun S, Glorieux T, Devaux J, Vreven J, Leloup G. Characterization of nanofilled compared to universal and microfilled composites. Dent Mater 2007; 23(1):51-9. https://doi.org/1016/j.dental.2005.12.003

[2] Ikejima I, Nomoto R, McCabe JF. Shear punch strength and flexural strength of model composites with varying filler volume fraction, particle size and silanation. Dent Mater 2003; 19(3):206-11. https://doi.org/10.1016/s0109-5641(02)00031-3

[3] George R. Nanocomposites: A review. J Dent Oral Biosc 2011; 2(3):38-40. https://doi.org/10.5368/JDOB/.2011.2.3.3.2

[4] Fortin D, Vargas MA. The spectrum of composites: New techniques and materials. J Am Dent Assoc 2000; 131(Suppl):26S-30S. https://doi.org/10.14219/jada.archive.2000.0399

[5] Chen MH, Chen CR, Hsu SH, Sun SP, Su WF. Low shrinkage light curable nanocomposite for dental restorative material. Dent Mater 2006; 22(2):138-45. https://doi.org/10.1016/j.dental.2005.02.012

[6] Manhart J, Kunzelmann KH, Chen HY, Hickel R. Mechanical properties and wear behavior of light-cured packable composite resins. Dent Mater 2000; 16(1):33-40. https://doi.org/10.1016/s0 109-5641(99)00082-2

[7] Yap AU, Teoh SH. Comparison of flexural properties of composite restoratives using the ISO and mini-flexural tests. J Oral Rehabil 2003; 30(2):171-7. https://doi.org/10.1046/j.1365-2842.2003.01004.X

[8] Eronat N, Candan U, Türkün M. Effects of glass fiber layering on the flexural strength of microfill and hybrid composites. J Esthet Restor Dent 2009; 21(3):171-8. https://doi.org/10.1111/j.1708-8240.2009.00259.x

[9] Scribante A, Bollardi M, Chiesa M, Poggio C, Colombo M. Flexural properties and elastic modulus of different esthetic restorative materials: Evaluation after exposure to acidic drink. Biomed Res Int 2019; 2019:5109481. https://doi.org/10.1155/2019/109481

[10] Scribante A, Massironi S, Pieraccini G, Vallittu P, Lassila L, Sfondrini MF, et al. Effects of nanofillers on mechanical properties of fiber-reinforced composites polymerized with light-curing and additional post curing. J Appl Biomater Funct Mater 2015; 13(3):e296-e299. https://doi.org/10.5301/jabfm.5000226

[11] Sfondrini MF, Gandini P, Tessera P, Vallittu PK, Lassila L, Scribante A. Bending properties of fiber-reinforced composites retainers bonded with spot-composite coverage. Biomed Res Int 2017; 2017:8469090. https://doi.org/10.1155/2017/8469090 
[12] Rodrigues Junior SA, Zanchi CH, Carvalho RV, Demarco FF. Flexural strength and modulus of elasticity of different types of resin-based composites. Braz Oral Res 2007; 21(1):16-21. https://doi.org/10.1590/s1806-83242007000100003

[13] Meenakumari C, Bhat KM, Bansal R, Singh N. Evaluation of mechanical properties of newer nanoposterior restorative resin composites: An In vitro study. Contemp Clin Dent 2018; 9(Suppl 1):S142-S146. https://doi.org/10.4103/ccd.ccd_160_18

[14] Abouelleil H, Pradelle N, Villat C, Attik N, Colon P, Grosgogeat B, et al. Comparison of mechanical properties of a new fiber reinforced composite and bulk filling composites. Restor Dent Endod 2015; 40(4):262-70. https://doi.org/10.5395/rde.2015.40.4.262

[15] Garoushi S, Säilynoja E, Vallittu PK, Lassila L. Physical properties and depth of cure of a new short fiber reinforced composite. Dent Mater 2013; 29(8):835-41. https://doi.org/10.1016/j.dental.2013.04.016

[16] Finan L, Palin WM, Moskwa N, McGinley EL, Fleming GJ. The influence of irradiation potential on the degree of conversion and mechanical properties of two bulk-fill flowable RBC base materials. Dent Mater 2013; 29(8):906-12. https://doi.org/10.1016/j.dental.2013.05.008

[17] International Organization for Standardization, Technical Committee. ISO 4049:2009. Dentistry — Polymer-Based Restorative Materials. $4^{\text {th }}$. ed. Geneva: ISO; 2009.

[18] Goracci C, Cadenaro M, Fontanive L, Giangrosso G, Juloski J, Vichi A, et al. Polymerization efficiency and flexural strength of low-stress restorative composites. Dent Mater 2014; 30(6):688-94. https://doi.org/10.1016/j.dental.2014.03.006

[19] Chung SM, Yap AU, Chandra SP, Lim CT. Flexural strength of dental composite restoratives: comparison of biaxial and three-point bending test. J Biomed Mater Res B Appl Biomater 2004; 71(2):278-83. https://doi.org/10.1002/jbm.b.30103

[20] Hamouda I, Elkader HA. Evaluation the mechanical properties of nanofilled composite resin restorative material. J Biomater Nanobiotechnol 2012; 3:238-42. https://doi.org/10.4236/jbnb.2012.32029 